\title{
A PEDAGOGIA DE PROJETOS DESENVOLVIDA EM MANAUS: UM ESTUDO DE CASO NA ESCOLA INDÍGENA KANATA T-YKUA
}

\author{
THE PEDAGOGY OF PROJECTS DEVELOPED IN MANAUS: A CASE STUDY \\ ABOUT AN INDIGENOUS KANATA T-YKUA SCHOOL
}

\author{
Raidrine Moçambite Viana ${ }^{1}$ \\ Universidade Federal do Amazonas - UFAM \\ Helenice Aparecida Ricardo2 \\ Universidade Federal do Amazonas - UFAM
}

\begin{abstract}
Resumo
O presente artigo apresenta resultados do projeto de pesquisa "A Pedagogia de Projetos desenvolvida em Manaus: Um estudo de caso na Escola Indígena Kanata T-Ykua", desenvolvido dentro das ações do Programa Institucional de Bolsas de Iniciação Científica (PIBIC) na Faculdade de Educação da Universidade Federal do Amazonas. O projeto teve como objetivo analisar a relevância e o alcance da Pedagogia de Projetos (PP) na escola indígena Kanata TYkua, seus conteúdos teórico-metodológicos e sua relação com a proposta pedagógica emanada da SEMED. A luta dos povos indígenas pelo ensino sistematizado pode ser compreendida como uma das formas de encarar as adversidades da sociedade envolvente, uma vez que a educação ofertada não possui um currículo diferenciado que revitalize e dê continuidade à sua cultura. Foi buscando a melhoria metodológica de suas práticas, que o povo Kambeba da comunidade Três Unidos inseriu a Pedagogia de Projetos no processo educacional da escola regular, visando à melhoria de seus processos socioculturais. Assim, considera-se necessário compreender como se desenvolvem esses projetos de aprendizagem na escola indígena Kanata T-Ykua. Os procedimentos metodológicos aplicados basearam-se no estudo de caso e na pesquisa bibliográfica e documental de cunho qualitativo. Como resultado, a pesquisa evidencia que os projetos são fundamentais para a revitalização e manutenção dos conhecimentos tradicionais do povo Kambeba, o que possibilita o desenvolvimento cognitivo e a aprendizagem dos alunos sobre as temáticas estudadas, valorizando os processos educativos indígenas com a integração do currículo de forma que o fazer pedagógico seja ressignificado.
\end{abstract}

Palavras-chave: Pedagogia de Projetos; escola indígena; conhecimentos tradicionais.

\footnotetext{
${ }^{1}$ Graduanda no curso de Licenciatura em Pedagogia na Faculdade de Educação (FACED) da Universidade Federal do Amazonas (UFAM), raidrinemoc@gmail.com

2 Mestra em Educação pela Faculdade de Educação (FACED) da Universidade Federal do Amazonas (UFAM), Especialista em Geografia do Amazonas pelo Departamento de Geografia (DEGEO) da Universidade Federal do Amazonas (UFAM), Professora de Geografia do curso de Formação de Professores Indígenas (FPI) da Universidade Federal do Amazonas (UFAM), helericardo@yahoo.com.br
} 


\section{Abstract}

This article presents results of the research project "The Pedagogy of Projects developed in Manaus: A Case Study About An Indigenous Kanata T-Ykua School" developed within the actions of the Institutional Program for Scientific Initiation Scholarships (PIBIC) at the Faculty of Education of the Federal University of Amazonas. The project aimed to analyze the relevance and scope of the Project Education (PP) in the indigenous school Kanata T-Ykua, their theoretical and methodological contents and its relation to the pedagogical proposal from the SEMED. The struggle of indigenous peoples for systematized teaching can be understood as one of the ways to face the adversities of the surrounding society, since the education offered does not have a differentiated curriculum that revitalizes and gives continuity to their culture. It was through seeking the methodological improvement of their practices, that the Kambeba people of the Três Unidos community inserted the Project Pedagogy in the educational process of the regular school, aiming at the improvement of their socio-cultural processes. Therefore, it is considered necessary to understand how these learning projects are developed in the Kanata T-Ykua indigenous school. The methodological procedures applied were based on the case study and qualitative bibliographical and documentary research. As a result, the research shows that the projects are critical to the revitalization and maintenance of traditional knowledge of Kambeba people, enabling cognitive development and student learning about the studied themes, valuing indigenous educational processes while shaping curriculum integration so that the pedagogical action is resignified.

Keywords: Project Pedagogy; Indigenous School; Traditional Knowledge.

\section{INTRODUÇÃO}

Preservar a cultura e a identidade dos povos indígenas parece ser algo cada vez mais difícil, tendo em vista que, progressivamente, essa identidade vem ganhando um novo caráter, conforme os povos indígenas encaram as adversidades e pressões decorrentes das organizações sociais da sociedade envolvente, num contínuo movimento de agregação à nação.

Em Manaus, há quatro escolas indígenas atualmente atendidas pela Secretaria Municipal de Educação (SEMED), localizam-se na área rural ribeirinha do município, sendo duas no Rio Negro (Yaymbwewa Rendawa Maku Arú Waimi e Kunya Taputira) e duas no Rio Cuieiras (Puranga Pisasú e Kanata T-Ykua), afluente do Rio Negro. Essas escolas não possuem um currículo próprio ou diferenciado, trabalhando com o mesmo currículo das escolas não indígenas.

Embora a matriz curricular das escolas indígenas não seja ainda diferenciada, elas buscam, por meio de projetos, fazer com que sua cultura, saberes e costumes não desapareçam, realizando a aproximação entre os saberes tradicionais e científicos e alinhando esses projetos com os conteúdos obrigatórios durante o ano letivo. É nesse contexto que a Pedagogia de Projetos surge nas escolas indígenas. 
A Pedagogia de Projetos consiste em uma educação que tem como objetivo vincular os conteúdos escolares aos conhecimentos e saberes produzidos no contexto social e cultural de uma comunidade. Segundo Leite (1996), a Pedagogia de Projetos tem o intuito de ressignificar o espaço escolar, possibilitando sua transformação em um espaço que permita interações e que se abra ao mundo real e a todas as suas dimensões e peculiaridades.

Desta forma, a Pedagogia de Projetos é vista como uma oportunidade de fortalecer o ensino tradicional de maneira complementar ao ensino científico, pois ela permite romper as divisas disciplinares, favorecendo os elos entre as diferentes áreas de conhecimento numa situação contextualizada da aprendizagem.

Portanto, a pesquisa buscou analisar a relevância dos projetos desenvolvidos na Escola Indígena Municipal Kanata T-Ykua, localizada na comunidade indígena Três Unidos, no rio Cuieiras, Manaus/Am. A análise se deu por meio do Estudo de Caso histórico-organizacional com a inspeção de documentos como o Projeto Político Pedagógico (PPP) da escola, o diário dos professores, a proposta curricular, os projetos realizados e os registros feitos pela SEMED na $V$ Mostra Pedagógica Indígena - " $D a$ Cultura dos Povos da Floresta Para as Telas do Mundo", realizada em agosto de 2011. Tais documentos foram analisados para apontar o alcance desses projetos e a real significância deles no processo de aprendizagem dos alunos da Escola Indígena Municipal Kanata T-Ykua.

\section{PRINCÍPIOS TEÓRICOS E PRINCIPAIS OBJETIVOS DA PEDAGOGIA DE PROJETOS}

Após o surgimento do movimento "Escola Nova", que veio com o propósito de se opor às práticas pedagógicas advindas da escola tradicional, vários educadores/pensadores de outros países tornaram-se conhecidos no Brasil através de Anísio Teixeira e Lourenço Filho. As ideias desses pensadores que representavam a "Pedagogia Ativa", sobretudo John Dewey (1859 - 1952) e Willian H. Kilpatrick (1871 1965) contribuíram para que fosse disseminado e conhecido no país o método de projetos.

John Dewey era filósofo, psicólogo e pedagogo, nascido nos Estados Unidos, tornou-se um dos educadores mais influentes e conhecidos do mundo todo, por ser um grande defensor da escola ativa. Nesta proposta de escola, os sujeitos aprendiam através da atividade pessoal. Dewey acreditava que a aprendizagem se estabelecia por meio do 
interesse do aluno, de forma que envolvesse suas próprias experiências e, nesse processo, o professor faria o papel de facilitador no desenvolvimento da procura pelo conhecimento que deve provir do próprio aluno.

Willian H. Kilpatrick foi pedagogo e professor de Educação na Universidade de Columbia-NY. Nascido nos Estados Unidos, foi aluno e sucessor de Dewey e de suas ideias progressistas. Como professor, Kilpatrick voltou sua atenção para as experiências dos alunos no processo de ensino-aprendizagem e, dando ênfase a algumas concepções de Dewey, iniciou a discussão sobre o trabalho com projetos como método educativo. Este método objetivava desenvolver nos alunos as possibilidades de busca e interesse pela pesquisa, compreendendo a finalidade de se trabalhar com diversas disciplinas ao mesmo tempo, de forma ativa, contextualizando e significando todo o processo para melhor entendimento por parte do aluno.

Atualmente, no Brasil, a docência, por meio de projetos como desenvolvido por Dewey e Kilpatrick, foi reinterpretada, deixando de ser vista como um simples método e assumindo uma postura pedagógica, uma forma de repensar não somente a escola e a matriz curricular que a ela atende, mas toda a prática pedagógica. Segundo Hernández (1998, p.64):

Os projetos de trabalho supõem, um enfoque do ensino que trata de ressuscitar a concepção e as práticas educativas na Escola, para dar respostas (não "a resposta") às mudanças sociais que se produzem nos meninos, meninas e adolescentes e na função da educação e não simplesmente readaptar uma proposta do passado e atualizá-la.

Dessa forma, entende-se que o projeto surge como uma forma de tornar a aprendizagem real, atrativa e significativa para o aluno. A Pedagogia de Projetos permite que os problemas e acontecimentos decorrentes de determinado contexto em sua globalidade possam ser analisados pelos educandos de maneira que possibilite a aproximação entre suas experiências e conhecimentos disciplinares.

\section{OBJETIVOS E PRINCIÍPIOS DA EDUCAÇÃO ESCOLAR INDÍGENA}

Antes mesmo de iniciarmos a discorrer sobre a educação escolar indígena, seus princípios e objetivos é necessário empreender o desafio de, reconhecendo as especificidades de cada etnia, compreender que elas carregam consigo processos educativos específicos fundamentados ao longo de seu desenvolvimento social.

Necessário pontuar que muitos desses processos são permeados de conflitos com os elementos da cultura "hegemônica" frutos de anos de colonização e extermínio. Por outro lado, salienta-se que as etnias indígenas apresentaram resistência cultural ao longo 
do processo colonial ainda em desenvolvimento, o que pode ser observado em diversas de suas manifestações históricas e contemporâneas.

A partir do reconhecimento das questões acima mencionadas, entende-se que a educação escolar indígena deve acima de tudo contribuir para a formação dos povos indígenas, promovendo a socialização dos saberes científicos ao mesmo tempo que busca resgatar e valorizar os saberes tradicionais de cada povo, buscando envolver todos os processos de socialização que permeiam esse processo.

Esta forma de conceber a Educação Indígena é corroborada por Gilberto (2014, p. 02), que afirma que:

As escolas indígenas foram criadas como um espaço para a formação escolar indígena, com o objetivo de preparar o índio para um convívio sócio-cultural e integrá-lo à sociedade brasileira, firmando também o seu espaço de formação cultural.

Nossa atenção inicial aos elementos da educação escolar indígena deve-se ao interesse de conhecer os princípios que norteiam as ações educativas dessas escolas, reconhecendo que a educação indígena é algo mais amplo, que implica a prática de socialização tradicional de cada povo, que considera a imitação como parte essencial do processo ensino-aprendizagem, e que, por isso, é contínua e múltipla.

Segundo o Referencial Curricular Nacional para as Escolas Indígenas - RCNEI (BRASIL, 1998, p. 23) os princípios da Educação Escolar Indígena, que baseiam a defesa dessa concepção de escola, são os seguintes:

Entre os povos indígenas, a educação se assenta em princípios que lhes são próprios, dentre os quais:

- uma visão de sociedade que transcende as relações entre humanos e admite diversos "seres" e forças da natureza com os quais estabelecem relações de cooperação e intercâmbio a fim de adquirir - e assegurar determinadas qualidades;

- valores e procedimentos próprios de sociedades originalmente orais, menos marcadas por profundas desigualdades internas, mais articuladas pela obrigação da reciprocidade entre os grupos que as integram;

- noções próprias, culturalmente formuladas (portanto variáveis de uma sociedade indígena a outra) da pessoa humana e dos seus atributos, capacidades e qualidades;

- formação de crianças e jovens como processo integrado; apesar de suas inúmeras particularidades, uma característica comum às sociedades indígenas é que cada experiência cognitiva e afetiva carrega múltiplos significados - econômicos, sociais, técnicos, rituais, cosmológicos.

Todavia, ainda que se tenha estabelecido uma série de avanços no sentido de promover a educação escolar indígena, construindo junto às etnias os mais diversos processos educativos, muito temos a desenvolver no campo da formação de professores, 
na constituição e concretização dos processos educativos por eles demandados e na efetivação do direito conclamado na Carta Magna de nosso país. Nesse sentido, acompanhamos o que afirmam Nery apud Santos e Pinheiro (2016, p. 25)

[...] há muitos desafios a serem enfrentados em questões que concernem aos direitos legais dos povos indígenas a uma educação própria e em outros casos o acesso pleno a educação básica intercultural de qualidade autonomia pedagógica/projeto político-pedagógico, formação inicial e continuada de professores indígenas, produção de materiais didáticos, construção/reforma/ampliação de infraestrutura, instalação de bibliotecas e equipamentos de informática.

No campo da gestão, contratação de professores indígenas a partir do reconhecimento dessa carreira específica no magistério e de outros profissionais atentando à organização social da comunidade e sua participação na avaliação de desempenho, melhorar a administração de programas como PNAE e PNATE, criar espaços de interlocução intercultural, formar técnicos/as para a gestão da EEI, gerir tendo o planejamento participativo, estratégico e compartilhado (TEEs) como diretriz.

A partir da análise sobre o quadro real de uma escola indígena no Brasil, podemos perceber o quanto ainda se precisa evoluir no campo da política educacional para os povos indígenas, sendo necessário priorizar os projetos societários e valorizar a cultura dos povos e das comunidades indígenas.

\section{A PRESENÇA DA PEDAGOGIA DE PROJETOS NAS ESCOLAS INDÍGENAS}

Levando em consideração que a pedagogia de projetos tem sido uma proposta pedagógica importante no sentido de resgatar e valorizar os saberes tradicionais dos povos indígenas, é essencial sabermos como funciona a dinâmica da pedagogia de projetos e como ela é aplicada nas escolas indígenas.

Nos estudos realizados, revela-se que a educação escolar indígena tem um caráter diferenciado por conter em suas diretrizes o ordenamento do ensino intercultural e bilíngue, objetivando a valorização ampla das culturas e comunidades indígenas e a preservação de suas pluralidades étnicas.

Desta forma, a pedagogia de projetos é uma ferramenta fundamental na modalidade escola indígena, pois ela possibilita que os educadores, junto com os educandos desenvolvam projetos de aprendizagem valorizando suas línguas, culturas e conhecimentos tradicionais.

Outros elementos aos quais a Pedagogia de Projetos (PP) dá ênfase é ao processo educativo e à experiência proporcionada por este processo. Esta pedagogia sustenta-se em princípios levantados pelo educador norte americano John Dewey e seu foco é a experiência do educando e seus saberes. A Pedagogia de Projetos surge no intuito de 
dinamizar o espaço escolar interrelacionando diversos conteúdos. Leite (1996, p. 32) destaca a seguinte questão:

Ao participar de um projeto, o aluno está envolvido em uma experiência educativa em que o processo de construção de conhecimento está integrado às práticas vividas. Esse aluno deixa de ser, nessa perspectiva, apenas um aprendiz do conteúdo de uma área de conhecimento qualquer. É um ser humano que está desenvolvendo uma atividade complexa e que nesse processo está se apropriando, ao mesmo tempo, de um determinado objeto de conhecimento cultural e se formando como sujeito cultural.

Acima de tudo, a Pedagogia de Projetos defende o trabalho educativo como processo coletivo no qual educandos e educadores concebem o espaço escolar como democrático e libertador. Essa proposta se faz relevante, posto que se traduz como instrumento de emancipação dos sujeitos e de construção de uma sociedade igualitária. Leite (1996) declara que a Pedagogia de Projetos é um caminho para transformar o espaço escolar em um espaço aberto à construção de aprendizagens significativas para todos que dele participam.

Podemos considerar que a Pedagogia de Projetos não é um método com objetivos e conteúdos pré-fixados, mas que busca trabalhar por meio de projetos considerando um trajeto que nunca é fixo, dando abertura para o desconhecido e para se pensar e contextualizar o processo de ensino/aprendizagem.

Dessa forma, podemos considerar que através da Pedagogia de Projetos, a escola indígena pode ser ressignificada, transformando-se em instrumento de valorização dos saberes tradicionais e dos processos próprios de aprendizagem das diferentes etnias. Consideramos ainda que, a Pedagogia de Projetos favorece a interculturalidade, uma vez que o desenvolvimento de projetos contribui tanto para a produção e reprodução do conhecimento próprio do povo indígena quanto facilita o acesso ao conhecimento científico.

\section{A ESCOLA INDÍGENA KANATA T-YKUA}

A Escola Indígena Municipal Kanata T-Ykua, localizada na comunidade indígena Três Unidos, no rio Cuieiras, Manaus - AM, pertencente à etnia Kambeba, foi implantada em 10 de outubro de 1993 com o nome de Escola Municipal Nossa Senhora da Saúde e oferta atendimento para a Educação Infantil e Ensino Fundamental I. Esta escola visa atender a necessidade da população indígena de acesso ao conhecimento estruturado e possibilita a manutenção dos saberes tradicionais e a confirmação da identidade do povo 
Kambeba. Essa implantação só foi possível por meio de muita luta e reivindicação dos indígenas e do Tuxaua Valdomiro Cruz Kambeba.

$\mathrm{Na}$ época da fundação, embora vinculada à Secretaria de Educação de Novo Airão, a escola não tinha prédio próprio e as aulas eram ministradas na casa do senhor Waldemir da Silva, atual Tuxaua da aldeia Três Unidos. Apenas em 1996, a prefeitura de Novo Airão construiu o prédio da escola, composto de um depósito de alimentação escolar e uma sala de aula.

Em 2003, a área onde a escola está localizada passou a pertencer ao município de Manaus e a escola começou a receber assistência da Secretaria Municipal de Educação de Manaus. Assim, em 2008, foi aprovado o ato de criação da Escola Municipal Três Unidos e por meio do Decreto Municipal 1.394/2011, que dispõe sobre a criação e o funcionamento das escolas indígenas, a escola passou a trabalhar formalmente a educação escolar indígena.

No ano de 2009, a escola estava em situação precária e com recursos próprios a comunidade se organizou e ergueu um novo prédio, contendo uma sala de aula, diretoria, depósito, cozinha e um pequeno refeitório.

Anos depois, em 2013, a Prefeitura de Manaus construiu um novo prédio, no mesmo local da escola anterior. Edificado em madeira e alvenaria, o prédio possuía uma sala de aula, biblioteca, telecentro, refeitório, diretoria, banheiros, cozinha, depósito de material escolar e depósito de merenda.

Em 2014, através da Lei no 1.893, de 23 de julho de 2014, a escola até então enquadrada na categoria de "Escola do Campo", teve seu decreto municipal de criação alterado para a categoria "Escola Indígena", recebendo o nome de Escola Indígena Municipal Kanata T-Ykua na língua Kambeba, que significa Luz do Saber, passando, assim, a usufruir dos direitos conferidos às instituições de educação escolar indígena.

Atualmente, o quadro de funcionários da escola é composto por dois professores indígenas da própria etnia Kambeba, um professor coordenador do Telecentro, uma merendeira, uma auxiliar de serviços gerais e um condutor da lancha escolar, que faz 0 transporte dos alunos que moram distantes da escola.

$O$ ano letivo da escola é diferenciado, as aulas acontecem nos dois turnos do dia, matutino e vespertino, de segunda a sexta. O calendário é elaborado pela SEMED e obedece ao calendário rural destinado às escolas ribeirinhas, que estabelece 0 funcionamento da instituição no período de janeiro a outubro, considerando as fases do rio. 


\section{O POVO KAMBEBA}

Conhecidos como o povo da província dos Água, em meados do século XVIII, os Kambeba, também chamados de Omágua, deixaram de se reconhecer como indígenas na Amazônia em virtude da violência e preconceito por parte de não indígenas da região, passando a se reconhecer como indígena somente a partir dos anos 1980, com o crescimento e fortalecimento dos movimentos indígenas e com a Constituição de 1988 que reconheceu os direitos indígenas.

Os Kambeba podem ser localizados atualmente em cinco aldeias do Amazonas, sendo quatro no Médio Solimões e uma no Baixo Rio Negro, mais precisamente no rio Cuieiras, afluente do rio Negro, onde fica localizada a Escola Municipal Indígena Kanata T-Ykua. Também podem ser encontrados no Alto Solimões, integrados aos Ticunas por conta da demarcação das terras indígenas.

Segundo a Associação dos Cambeba do Alto Solimões, existem hoje aproximadamente 1.500 Kambebas na região do Alto Solimões, constituindo 223 famílias que estão iniciando seu processo de afirmação étnica com o suporte dos Kambeba do Médio Solimões.

$\mathrm{Na}$ comunidade Três Unidos poucos são os que dominam a língua Omágua/Kambeba, (cerca de cinco falantes desse idioma) por isso a educação escolar busca revitalizar a língua tradicional e utilizá-la como língua de transmissão de conhecimento. A língua Kambeba é pertencente ao tronco Tupi, família Tupi-Guarani (RODRIGUES, 1986), porém a língua mais falada na aldeia é o Português.

O povo Kambeba convive diretamente com a natureza e dela extrai subsídios para sua subsistência. A atividade econômica mais comum é o artesanato, ao qual se dedicam homens e mulheres. Ademais, na aldeia há empreendedores, técnicos em enfermagem, professores e outros funcionários públicos. O principal meio de economia dos Kambeba da comunidade Três Unidos atualmente é o turismo, toda quarta-feira a comunidade recebe turistas e apresenta sua cultura, danças, ritos, artesanatos, etc.

\section{RESULTADOS E DISCUSSÕES}

Durante o desenvolvimento da pesquisa, foram analisados diversos arquivos em que constavam documentos referentes aos projetos desenvolvidos na Escola Indígena Kanata T-Ykua, com o objetivo de analisar a relevância e o alcance desses projetos para a aprendizagem dos alunos. A partir disso, observamos que não é oferecido a contento o 
suporte pedagógico-metodológico específico e diferenciado à modalidade de educação escolar indígena pela Secretaria Municipal de Educação (SEMED), o que dificulta o trabalho dos professores indígenas no que se refere à metodologia e planejamento, entre outros desafios encontrados, como a formação de turmas em classes multisseriadas.

Em Manaus, existem hoje quatro escolas municipais indígenas. As quatro, que até o ano de 2014 estavam enquadradas na categoria de "Escola do Campo", tiveram seus decretos municipais de criação alterados para a categoria "Escola Indígena", recebendo, inclusive, denominações nas línguas maternas dos povos predominantes nas comunidades onde se localizam.

No Rio Negro, estão localizadas as Escolas Indígenas Municipais Yaymbwewa Rendawa Maku Arú Waimi, na comunidade Terra Preta; e a Escola Indígena Municipal Kunya Taputira, na comunidade São Tomé.

No Rio Cuieiras, além da Escola Indígena Kanata T-Ykua, objeto de nossa pesquisa, localizada na comunidade Três Unidos, também se localiza a Escola Indígena Puranga Pisasú, na comunidade Nova Esperança.

Todas as escolas atendem demandas da educação infantil e séries iniciais do ensino fundamental (Fundamental I, $1^{\circ}$ ao $5^{\circ}$ ano), com professores indígenas indicados pelas comunidades para atuar nesses níveis e etapas de ensino.

A Escola Indígena Puranga Pisasú oferta atendimento escolar para alunos das séries finais do Ensino Fundamental (Fundamental II, 6o ao 9o ano), no entanto os professores que atuam nessa etapa do ensino fundamental não são professores indígenas.

Entre as quatro comunidades que possuem Escolas Indígenas, apenas a comunidade Três Unidos não é formada por indígenas predominantemente do povo Baré. Nesta comunidade, a predominância é Kambeba.

$\mathrm{Na}$ falta de uma matriz curricular diferenciada que atenda às escolas indígenas, anualmente a Escola Indígena Kanata T-Ykua desenvolve um projeto com o intuito de revitalizar a cultura e a língua do povo Kambeba.

A definição do tema do projeto a ser trabalhado ocorre no início do ano letivo através de uma reunião com toda a comunidade, visando à melhoria do desempenho metodológico das práticas tradicionais, respeitando o currículo nacional. Este procedimento está de acordo com o Artigo 210 da Constituição Federal, que estipula conteúdos mínimos para o ensino fundamental como forma de valorizar os processos de aprendizagem e a identidade indígena. 
Os professores, por meio da pedagogia de projetos, desenvolvem ações que valorizam os conhecimentos tradicionais. Ao analisar a matriz curricular das escolas municipais de Manaus, a autora constata que é visível a ausência de temas que remetem à cultura popular e aos povos indígenas:

O currículo de nossas escolas tem desqualificado tanto os saberes e os conhecimentos, quanto a música, o rap, o brega, o funk, o forró e os gostos populares; não reconhece como válidos os modos de viver, trabalhar e proceder das culturas populares e indígenas; e não valoriza os ideais e as visões de mundo dos grupos sem poder (WEIGEL, 2006, p. 59).

Os projetos pedagógicos são pensados e estruturados para garantir aos alunos a autoidentificação e valorização do seu povo, das suas tradições e cultura, integrando o conhecimento científico com o tradicional, valorizando os conhecimentos da etnia Kambeba e contribuindo no atendimento das necessidades da comunidade, bem como para a transformação social.

\section{DOS TEMAS TRABALHADOS}

Os mais variados temas são trabalhados nos projetos de aprendizagem, todos com a aprovação da comunidade e com relevância social e cultural para os Kambeba. De acordo com John Dewey ${ }^{3}$, a educação é compreendida como o modo pelo qual o sujeito estuda o mundo e adquire, ao mesmo tempo, conhecimentos de significados e valores. A partir desse entendimento, os projetos desenvolvidos na escola partem da epistemologia dos conhecimentos tradicionais, em diálogo com os conhecimentos científicos globais.

Todo o aprendizado é construído em estreita relação com o contexto em que os alunos estão inseridos. Dessa forma, os temas trabalhados nos projetos partem do saber tradicional do povo Kambeba, contribuindo para o fortalecimento da identidade e da cultura e motivando alunos e professores na busca de outros conhecimentos.

Por meio da listagem enviada pelo gestor da Escola Indígena Kanata T-Ykua, chegamos aos seguintes temas, que foram trabalhados na escola por meio de projetos até o presente:

\footnotetext{
3 DEWEY, John. Democracia e educação. 3.ed. Tradução de Godofredo Rangel e Anísio Teixeira. São
} Paulo: Nacional, 1959. 


\section{Quadro 1 - Temas desenvolvidos}

\begin{tabular}{l|c}
\hline Ano & Tema \\
2008 & Pinturas corporais Kambeba \\
2009 & Comidas tradicionais Kambeba \\
2010 & O formato das casas Kambeba \\
2011 & A cerâmica Kambeba \\
2012 & Músicas Kambeba \\
2013 & Roupas Kambeba \\
2014 & Os artesanatos Kambeba \\
2015 & Utensílios de caça e pesca \\
2016 & Plantas medicinais do povo Kambeba \\
2017 & Fortalecendo o uso das plantas medicinais do povo Kambeba \\
\hline
\end{tabular}

Fonte/créditos: Produzido pelas autoras

A sistematização da abordagem de forma interdisciplinar e integrada parte do tema gerador, que possibilita a criação de procedimentos metodológicos de exploração nos mais variados campos de conhecimento, tendo como ponto de partida para a aprendizagem os saberes tradicionais do povo Kambeba, ou seja, os conteúdos curriculares são adaptados ao contexto em que os alunos estão inseridos.

Neste ano letivo de 2018, o projeto pedagógico trabalhado na escola, refere-se à revitalização da cultura Kambeba através da dança, intitulado "Fortalecendo as danças indígenas do povo Kambeba na aldeia Três Unidos", com o objetivo geral de utilizar as danças indígenas no processo de ensino e aprendizagem da língua Kambeba, e com o objetivo específico de possibilitar aos educandos o conhecimento da história e dos aspectos mitológicos das danças indígenas do povo Kambeba, o que incentiva a prática das danças na aldeia e a prática bilíngue na escola e no meio familiar.

\section{AÇÕES}

As ações que serão realizadas no decorrer dos projetos são elencadas em um cronograma para definir o que será executado em cada mês do ano. Essas ações são todas desenvolvidas com o envolvimento da comunidade em geral, desde o ancião da aldeia até o mais novo, de forma que seja promovida a integração entre a escola e a comunidade, entre as pessoas e a reflexão acerca da relevância do projeto, com intuito de estabelecer uma consciência escolar comunitária. 
Os projetos buscam explorar estratégias metodológicas nas diversas áreas de conhecimento, de forma contextualizada e diversificada, envolvendo pesquisa de campo, nas quais os alunos juntamente com o professor coletam dados para análise. Em momento posterior, o professor relaciona o que foi observado no contexto da comunidade com os conteúdos curriculares, dando novos sentidos e significados à aprendizagem, valorizando a língua portuguesa e, sobretudo, a língua materna. De acordo com Leite (1996, p.32):

O trabalho com projetos traz uma nova perspectiva para entendermos 0 processo de ensino/aprendizagem. Aprender deixa de ser um simples ato de memorização e ensinar não significa mais repassar conteúdos prontos. Nessa postura, todo conhecimento é construído em estreita relação com o contexto em que é utilizado, sendo, por isso mesmo, impossível separar os aspectos cognitivos, emocionais e sociais presentes nesse processo. A formação dos alunos não pode ser pensada apenas como uma atividade intelectual. É um processo global e complexo, onde conhecer e intervir no real não se encontram dissociados.

No projeto desenvolvido em 2017, intitulado "Fortalecendo o uso das plantas medicinais do povo Kambeba", foram realizadas diversas ações com os objetivos de promover a socialização dos conhecimentos das práticas de cura por meio da medicina tradicional; incentivar o plantio e o cultivo das plantas medicinais; facilitar a prática bilíngue na escola e no meio familiar, através dos temas referentes às plantas medicinais; e valorizar a medicina tradicional da aldeia. Para alcançar estes objetivos, foi feito o levantamento das plantas existentes na comunidade através de entrevistas aos mais velhos e visitas a todas as casas para verificar os tipos de plantas que cada família cultiva. Todas as informações colhidas foram catalogadas de modo que fosse identificada a contribuição e uso de cada planta medicinal. Em seguida, foram executadas mostras de plantio e cultivo, das técnicas utilizadas pelos povos indígenas para realização de remédios naturais e de como se realiza o manejo, a preparação e o armazenamento dos remédios.

\section{PRÁTICA PEDAGÓGICA}

Ainda que a proposta pedagógica que atende a escola indígena municipal Kanata T-Ykua seja emanada da SEMED e não tenha em suas diretrizes o ordenamento específico, diferenciado, intercultural e bilíngue, a escola busca sua autonomia nos processos, levando em consideração os tempos e espaços educativos subjetivos da cultura Kambeba. 
O trabalho com projetos possibilita a adaptação dos conteúdos curriculares à realidade e contexto da comunidade, priorizando uma prática pedagógica fundamentada no respeito da realidade do aluno e no diálogo crítico. Behrens (2006, p.33) afirma que a utilização de projetos "aparece com o sentido de proposição de uma prática pedagógica crítica, reflexiva e problematizadora".

A presença e envolvimento da família, e comunidade em geral, é essencial para o desenvolvimento do processo educativo, tendo em conta que é dever da escola indígena propiciar esse vínculo entre a educação escolar e a própria vida do educando, em sua prática histórica.

Por conseguinte, o processo de ensino/aprendizagem ganha uma nova perspectiva, os conteúdos passam a ter significados e se constituem em poderosos mecanismos de compreensão da realidade.

\section{CONSIDERAÇÕES FINAIS}

O desenvolvimento do presente estudo possibilitou uma análise de como a Pedagogia de Projetos é relevante na escola indígena, marcadamente na Kanata T-Ykua. Além disso, permitiu por meio de pesquisa bibliográfica, documental e observação direta, a obtenção de dados mais consistentes para o desenvolvimento das etapas do trabalho, de forma que novos parâmetros e referências foram surgindo.

O trabalho com projetos, partindo de um tema gerador que atenda às necessidades da comunidade e que revitalize a língua e a cultura Kambeba, permite que os estudantes indígenas se autoidentifiquem, se valorizem e valorizem o seu povo, expressando e enriquecendo os saberes tradicionais, desenvolvendo o cognitivo, ressignificando o fazer pedagógico de modo que o espaço de aprendizagem não se limite às paredes da escola.

A integração do currículo possibilita que os alunos, por meio dos conhecimentos tradicionais, desenvolvam os conhecimentos científicos universais, visando à transformação social por meio da valorização dos conhecimentos próprios da etnia Kambeba.

A escola Kanata T-Ykua parte da epistemologia dos conhecimentos tradicionais para potencializar o ensino-aprendizagem dos conteúdos científicos visando o bom desempenho dos alunos nas provas realizadas pela Secretaria Municipal de Educação (SEMED) para avaliação das escolas indígenas.

Portanto, fica evidente a relevância do desenvolvimento da Pedagogia de Projetos, não apenas para a aprendizagem dos conteúdos científicos, mas também para a 
revitalização da língua Kambeba, das danças, dos rituais, da culinária, do artesanato, da história antiga, do uso da medicina tradicional e de outros costumes. Importante ainda salientar, o alcance que esses projetos têm ao envolver toda a comunidade no processo de ensino/aprendizagem.

Apesar dos avanços, consideramos que ainda se faz necessário avançar muito no que concerne ao suporte pedagógico-metodológico específico e diferenciado à modalidade de educação escolar indígena que atualmente não é oferecido a contento pela Secretaria Municipal de Educação (SEMED).

\section{REFERÊNCIAS}

BRASIL, Educação Escolar Indígena: diversidade sociocultural indígena ressignificando a escola/Ministério da Educação e do Desporto, Secretaria de Educação Continuada, Alfabetização e Diversidade. - Brasília: MEC/SECAD, 2007.

BRASIL, Referencial curricular nacional para as escolas indígenas/Ministério da Educação e do Desporto, Secretaria de Educação Fundamental. - Brasília: MEC/SEF, 1998.

BEHRENS, Marilda Aparecida. Paradigma da complexidade: metodologia de projetos, contratos didáticos e portifólios. Petrópolis, RJ: Vozes, 2006.

D'ANGELIS, Wilmar da Rocha. Aprisionando Sonhos: a educação escolar indígena no Brasil / Wilmar da Rocha D’Angelis - Campinas, SP: Curt Nimuendajú, 2012.

DEWEY, John. Democracia e educação. 3.ed. Tradução de Godofredo Rangel e Anísio Teixeira. São Paulo: Nacional, 1959. . Reconstrução e filosofia. São Paulo: Nacional, 1955. . Experiência e educação. 3.ed. Tradução de Anísio Teixeira. São Paulo: Nacional, 1979.

GILBERTO, Irene Jeanete Lemos. EDUCAÇÃo INDÍGENA E FORMAÇÃo DE PROFESSORES. Anped 2014

HERNANDÉZ, Fernando; VENTURA, Montserrat. A organização do currículo por projetos de trabalho. Porto Alegre: Artmed, 1998.

KILPATRICK, William Heard. Educação para uma civilização em mudança. 16.ed. Tradução de Noemy Rudolfer. São Paulo: melhoramentos, 1978. 
LEITE, Lúcia Helena Alvarez. Pedagogia de projetos: intervenção no presente. Revista Presença Pedagógica. Ed 8. Mar/Abr.

MELIA, Bartolomeu. Educação indígena e alfabetização. Ed. Loyola, 1979.

PEREIRA, Laïs de Toledo Krücken; GODOY, Dalva Maria Alves; TERÇARIOL, Denise. Estudo de caso como procedimento de pesquisa científica: reflexão a partir da clínica fonoaudiológica. Psicol. Reflex. Crit. vol.22 no.3 Porto Alegre 2009

RODRIGUES, A.D. Línguas brasileiras: para o conhecimento das línguas indígenas. São Paulo: Edições Loyola, 1986.

SANTOS, Jonise Nunes. Educação Escolar Indígena em Manaus (2005 - 2011). / Jonise Nunes Santos; Maria das Graças Sá Peixoto Pinheiro. - Manaus: Editora Valer/ FAPEAM, 2016.

WEIGEL, Valéria Augusta de Medeiros. Escola de branco em malokas de índio. Manaus: Editora da Universidade do Amazonas, 2000.

Sociedade, Cultura e Educação: Uma abordagem Antropológica. BRITO, Luiz Carlos Cerquinho de. (org.). Sociedade, Educação e Formação do Sujeito. Manaus: EDUA, CEFORT/UFAM, 2006. 